\title{
O estudo da 'forma-dinâmica' urbana através do mapping de dinâmicas sociais e da apropriação espacial
}

\author{
David L. Viana \\ Centro de Investigação do Território, Transporte e Ambiente (CITTA), Faculdade de \\ Engenharia da Universidade do Porto, Rua Dr. Roberto Frias, 4200-465 Porto, Portugal. \\ Escola Superior Gallaecia (ESG) Largo das Oliveiras, 4920-275 Vila Nova de Cerveira, \\ Portugal. E-mail: david.leite.viana@esg.pt
}

$\mathrm{e}$

\author{
Isabel C. Carvalho \\ Centro de Investigação em Artes e Comunicação (CIAC), Universidade do Algarve \\ Campus Gambelas, FCHS, 8005-139 Faro, Portugal. \\ E-mail: isabel.cristina.carvalho04@gmail.com
}

Artigo revisto recebido a 16 de Abril de 2016

\begin{abstract}
Resumo. $O$ artigo aprofunda a correlação entre forma urbana e mapeamento de dinâmicas sócio-espaciais, decorrentes do rastreamento de fluxos urbanos com recurso a dispositivos comunicacionais móveis (por exemplo, smartphone $e$ tablet). Entende-se que deve ser incluído na análise morfológica o desdobramento com que atualmente se experiência espaços urbanos, exponenciado pela conexão digital e acesso à internet, com apoio de plataformas digitais que processam grande diversidade de dados individuais e coletivos (exploratórios e estruturados), para além de georreferenciados em tempo real. A profusão de atividades e usos que ocorrem nos espaços urbanos requer o reconhecimento que os fluxos são aspetos-chave na análise da forma urbana. Considera-se determinante rastrear vivências urbanas, mapeando-as. $O$ argumento apresentado prende-se com a convergência da noção de 'formadinâmica' urbana e o desenvolvimento de mapping de dinâmicas sociais e da apropriação espacial. Alude-se à interoperatividade e à multidimensionalidade de leituras processadas em modo combinatório na análise morfológica, amplificando o estudo da forma urbana. A inter-relação de métodos de análise morfológica deverá tornar explícitas, estruturadamente, regras implícitas de dinâmicas detetadas na forma urbana, consolidando a interdependência entre configuração física do sistema espacial, a perceção que dele se tem e que padrões de apropriações se conformam nos espaços urbanos.
\end{abstract}

Palavras-chave: análise morfológica, 'forma-dinâmica' urbana, mapping, dinâmicas sociais, apropriação espacial

O artigo compreende a articulação da investigação desenvolvida pelos autores no âmbito do estudo da forma urbana combinando abordagens morfológicas qualitativas e quantitativas, o recurso a dispositivos comunicacionais móveis (smartphones e tablets), a produção de mapeamentos digitais (rastreamentos individuais na experiência pessoal de espaços urbanos) e a realização de mapas coletivos assentes em plataformas digitais (em modo open source). Considerando que a análise 
morfológica deve processar-se de forma integrada $\mathrm{e}$ atendendo ao potencial que ferramentas digitais de georreferenciação têm na apreensão e perceção de espaços urbanos, conjuga-se ambas com a perspetiva que a cidade se confronta com lógicas de urbanização assimétricas e, muitas vezes, exógenas a estratégias e planos urbanos. Tendo em linha de conta o cuidado com o papel que os cidadãos podem assumir neste processo, norteia-se o texto no sentido da valorização e inclusão de dinâmicas urbanas quotidianas (promovidas individual ou coletivamente) na leitura da forma da cidade. Contempla-se a configuração urbana no quadro dos fluxos e atividades diárias que nela decorrem, sabendo que em muitas cidades (onde a principal 'infraestrutura' é a humana) este é o meio pelo qual os seus espaços urbanos são conformados.

Não diminuindo, ou excluindo, o 'tradicional' estudo da forma urbana e sua estrutura física, procura-se determinar $\mathrm{o}$ enlaçamento entre este e novas possibilidades de compreensão de espaços urbanos através do potencial que as plataformas digitais e os dispositivos comunicacionais móveis acrescentam à apreensão urbana. Smartphones e tablets fazem parte das vivências urbanas e a partir deles - é possível reconhecerem-se novas dimensões espaciais, que se desdobram entre o físico e o virtual, o analógico e o digital, o visível e o invisível, o tempo e o espaço. Estando a par do desenvolvimento tecnológico que se regista nestas áreas, com a incorporação de Global Positioning System (GPS) em diversas aplicações informáticas presentes em dispositivos comunicacionais móveis, justifica-se a investigação sobre como incorporar no estudo da forma urbana a quantidade de dados georreferenciados que podem ser diariamente produzidos pela população. Referem-se a percursos, atividades, permanências, vivências, sensações, apropriações e usos que se desenrolam nos (e entre) espaços urbanos que devem ser equacionados no estudo da forma da cidade.

Se a pesquisa tecnológica e as plataformas digitais têm incrementado modos de participação cívica (ativa e direta) no planeamento e em processos colaborativos de transformação de espaços urbanos (com os quais os citadinos se relacionam diariamente), ganhando corpo o e-planning, vislumbra-se a necessidade de convergir no estudo 'tradicional' da forma urbana a informação resultante de sistemas digitais de rastreamento de atividades urbanas e de tipos de apropriação espacial, refletindo dinâmicas sociais na forma urbana. $\mathrm{O}$ artigo aproxima campos do conhecimento que se encontram algo distantes quando colocados à luz do estudo da forma urbana, nomeadamente no que se refere à análise morfológica no quadro da transitoriedade que caracteriza a configuração de espaços urbanos surgidos no contexto da urbanização não estruturada e da indefinição morfológica que marca partes extensas e significativas de cidades atuais. $\mathrm{O}$ que se apresenta no artigo encontra eco em espaços urbanos destituídos de uma composição clara e regular, mas - mesmo assim - revelam-se repletos de marcas e significados que vale evidenciar e descodificar, tornando explícitas regras implícitas - para que o estudo da forma urbana se torne mais informado e revelador dos modos de vida que nela acontece.

\section{Da forma urbana à 'forma-dinâmica' urbana na análise morfológica}

O desenvolvimento verificado na produção de cartografia, articulando o analógico e o digital, entrecruzando plataformas digitais na coleta, tratamento e processamento de dados, proporciona processos de mapeamento que enriquecem o estudo da forma urbana aumentando o tipo de informação correlacionada e acrescentando categorias de análise morfológica. Como mencionado, é possível desdobrar o modo como indivíduos e população em geral participam ativa e diretamente no reconhecimento multidimensional de lugares da cidade, expressando impressões pessoais, comentando-os subjetivamente de forma georreferenciada e anotando-os em tempo real - relatando pontos de vista, sensações, emoções, ações, apropriações, fluxos e usos que resultam da relação que estabelecem entre si e os espaços urbanos. Consolida-se o enlaçamento da apreensão e da perceção espacial com o conjunto de atividades que ocorre em diferentes sítios da cidade traduzido em mapas colaborativos assentes em plataformas digitais. Deste enquadramento, 
sobressai o contributo que os mapas de dinâmicas e / ou mapeamentos dinâmicos outorgam a abordagens morfológicas qualitativas e quantitativas (como a space syntax).

Surgem âmbitos de análise relacionais e interdependentes, convergindo dialogicamente a dimensão física da estrutura da cidade com os fluxos que ocorrem entre espaços urbanos, tornando possível compreender não só a forma urbana, mas também as respetivas dinâmicas quotidianas que nela se geram. Desta relação, avança-se para a noção de forma-dinâmica urbana (Viana, 2015), que tem implícita a perspetiva que a cidade conhece processos de transformação que não respondem apenas ao planeamento e à gestão urbanística. Não obstante esta situação não ser nova na conformação continuada de espaços urbanos, o que se afigura assinalável prende-se com a aceleração com que tal acontece. Ou seja, é do conhecimento geral que a maior parte da população mundial é urbana (e não rural tendendo a acentuar-se esta situação). No entanto, é também sabido que a rápida urbanização tem ocorrido principalmente fora de figuras de planos ou estratégias territoriais e urbanas capazes de estabelecerem os termos da urbanização 'galopante'.

$\mathrm{Na}$ senda do desfasamento entre o projetado e o ocupado / apropriado, ganha corpo a urbanização auto-organizada, de oportunidade, pragmática, assente em micro / múltiplas iniciativas individuais que reconfiguram espaços urbanos, dilatam regras, distendem padrões e redefinem elementos urbanos (Coelho, 2013).

Aspetos sobre a ocupação de espaços urbanos têm sido abordados no sentido de os enquadrar em disciplinas e saberes como a antropologia do espaço, a sociologia urbana, a economia urbana e dos recursos, as teorias da complexidade ('complexidade organizada'), entre outras aproximações científicas (Castells, 1972; Jacobs, 1961; Trancik, 1986). O conhecimento resultante tem contribuído para a investigação em arquitetura e urbanismo, complementando perspetivas estritamente focadas na dimensão física da evolução da cidade (Moughtin, 1996; Panerai et al., 1980; Salingaros et al., 2011; Venturi et al., 1977). O incremento inter e / ou transdisciplinar, visando o entendimento de fenómenos citadinos conjuntamente com a atenção aos tipos de apropriação e produção de espaços urbanos, tem confirmado preocupações cada vez mais presentes em âmbitos morfológicos (Aymonino, 1977; Caro e Rivas, 1985; Lefebvre, 1968; Salingaros, 2011).

Associando-se a esta problemática a rápida evolução tecnológica (e a sua facilidade de manuseamento e aquisição) - disponibilizando interfaces simplificadas e intuitivas (ao nível do explorar célere e detalhado de espaços urbanos) - constata-se a alteração de paradigmas sobre tempo, espaço, informação, modos de estar / relacionar na cidade e experienciar e partilhar momentos e vivências urbanas. Defende-se que o estudo da forma urbana precisa saber acolher a indeterminação, indefinição e incerteza associada a processos de urbanização, passando a integrar dinâmicas sócio-espaciais individuais e subjetivas, incluindo fluxos e usos pessoais fomentados a partir de lógicas relacionais que devem estar presentes na análise morfológica. Constituem, por exemplo, fluxos energéticos e de capital, redes de transporte e de informação, sistemas produtivos e de comércio local / internacional, fenómenos migratórios e de densificação urbana, entre outros fatores conducentes à híper-urbanização e / ou urbanização acelerada. A configuração da cidade extravasa limitações físicas e expande-se para dimensões emocionais, com base em conexões interpessoais e virtuais. Conceitos como distância, sociabilização, interação e participação cívica ganham contornos 'elásticos' e flexíveis. A este propósito, Ortega e Bayón (2015, p. 19) referem que: 'Vizinhos e visitantes que são estranhos caminham juntos e mapeiam os problemas da sua cidade como uma comunidade. Isto envolve o reconhecimento que a observação dos espaços urbanos se torna mais crítica e profunda quando se está conectado e se age a partir de uma rede. Uma rede pode multiplicar os seus principais pontos através de narrativas ‘transmidiáticas'. As pessoas a passear muitas vezes compartilham as suas fotografias e histórias no local usando dispositivos portáteis e aplicativos colaborativos de geolocalização (como openstreetmap). Isso torna o caminhar em si uma experiência interativa híbrida que é ao mesmo tempo física e virtual, uma expressão que mescla o corpo e elementos digitais. A cidade é um palco onde espaços 
públicos e a internet se tornam híbridos em alta velocidade social sob diferentes nomes (cidade compartilhável, cidade nómada, cidade senciente). Redes físicas e redes digitais interagem como cultura P2P (pessoa a pessoa), ajudando a desenvolver um modelo emergente de cidadania, que é autoorganizado, crítico e, acima de tudo, altamente interativo.' (tradução livre dos autores)

$\mathrm{Da}$ passagem anterior, verifica-se um paradigma urbano emergente que, como indicado, atende à concentração da focagem do estudo da cidade na dimensão não apenas física (própria do respetivo suporte material) mas também no conhecimento científicosocial de dinâmicas relativas às transformações ocorridas em espaços urbanos intrincados, densos e complexos em termos espácio-culturais (Viana, 2015). Neste sentido, os dispositivos comunicacionais móveis aliam à mobilidade diversas possibilidades de coleta e análise de dados, cujo tratamento e processamento se tornam cada vez mais rápidos, aos quais se associa uma crescente velocidade de transmissão de informação produzida - a que Lemos (2009a) designa de 'mobilidade ampliada', caracterizando (deste modo) a sociedade atual como 'sociedade de informação' (também denominada por Castells, 1999 [2002], de 'sociedade em rede').

Promovida pelo que Jenkins (2006) intitula de 'convergência mediática', comunidades e redes de conexões (reais e/ou virtuais organizadas em lógicas de cooperação) permitem a troca de vivências, experiências e perceções que questionam o que 'regularmente' se enquadra no estudo da forma da cidade e respetivos elementos urbanos, implicando não só ampliar tipos de fontes e recolha de dados, mas também reestruturar o seu processamento e reorganizar o conhecimento decorrente complementando, na análise morfológica, o que pode ser mensurável e corresponde a tendências e padrões (a regra, a permanência e a repetição), com o que usualmente é considerado de imensurável e indexado ao 'indigente' e à exceção (o 'caótico', o provisório e a diferença).

De acordo com Vegara e Rivas (2004, p. 247), compreender 'a sociedade em rede, a importância das redes e seus fluxos, dos nós e das suas interações, afeta qualquer estratégia territorial e, evidentemente, afetará em grande medida o desenho das cidades do futuro.' (tradução livre dos autores)

Os lugares das cidades, onde impera a tríade ciência - tecnologia - informação, transformam-se em espaços flexíveis, comunicacionais, lugares digitais (Horan, 2000) - isto é, ambientes urbanos de conexão permanente. As tecnologias móveis sem fio proporcionam novas práticas de agregação e apropriação social no espaço urbano. As novas tecnologias digitais, as redes telemáticas e a sociedade de informação reconfiguram os espaços urbanos, visto que, conforme Vegara e Rivas (2004, p. 257): 'Os princípios que orientam o desenho dos lugares digitais são os de localização fluída, garantia de interação entre lugares e fluxos, plenitude de significado na sinergia entre espaço físico e virtual, conexões no limiar que permitem a conectividade entre ambas realidades (...).' (tradução livre dos autores)

Assim, os espaços urbanos alteram-se, permitindo novas funções, interações $\mathrm{e}$ sociabilidades: a tríade 'espaço urbano-espaço eletrónico-interação social' caracteriza o que Silva (2006) classifica de 'espaços híbridos'. Por seu lado, Santaella (2008) refere-se a eles como 'espaços intersticiais' e Lemos (2009a) considera-os de 'territórios informacionais'. Ainda segundo este mesmo autor (Lemos, 2009a, p. 33): 'Devemos definir os lugares, de agora em diante, como uma complexidade de dimensões físicas, simbólicas, econômicas, políticas, aliadas a banco de dados eletrônicos, dispositivos e sensores sem fio, portáteis e eletrônicos, ativados a partir da localização e da movimentação do usuário. Esta nova territorialidade compõe, nos lugares, o território informacional.'

Visto isto, as interfaces tecnológicas permitem a interação entre redes físicas, sociais e digitais, alterando a perceção da espacialidade, temporalidade, público/privado, territorialização e desterritorialização. $\mathrm{O}$ virtual envolve-se com o real através da perceção sensorial. Citando Lemos (2007, p. 11): 'A novidade não é a transformação do urbano pelos artefactos e processos sociotécnicos, mas a particularidade dessas transformações. Espaço, mobilidade e tecnologia formam o tripé para $a$ compreensão das médias locativas em sua relação com a ciberurbe. Mais do que o abandono das cidades pelas tecnologias do 
ciberespaço, o que estamos vendo são novas práticas de uso do espaço urbano pelo deslocamento com artefactos digitais e processos de localização por redes sem fio.'

Jenkins (2006) entende 'cultura de convergência' como processo no qual diferentes médias coexistem e se complementam (embora não dependam uns dos outros), assente em três pilares: inteligência coletiva, cultura participativa e convergência mediática. Neste âmbito, a internet consubstancia um contexto alargado de informações, onde é possível exponenciar a produção de conhecimento e estabelecer relações. No entanto, sobre esta questão, importa referenciar Castells (1999 [2002], p. 50): '(...) O que caracteriza a atual revolução tecnológica não é a centralidade de conhecimentos e informações, mas a aplicação deste conhecimento e desta informação para a geração de conhecimentos e de dispositivos de processamento e comunicação da informação, num ciclo de realimentação cumulativo entre a inovação e seu uso.'

Neste quadro, a noção de forma-dinâmica urbana, complementando o conceito de forma urbana, promove a análise morfológica integrada, contemplando processos individuais e subjetivos de conformação de espaços urbanos, entendidos a partir de lógicas interatuantes e interdependentes entre estrutura física, dinâmicas sociais e fluxos de atividades, legitimando e incluindo a diversidade de modos de apropriação espacial (Viana, 2015). Considera-se que o estudo da forma urbana deve abranger relações entre dinâmicas sociais e a apropriação espacial e o modo como ambas se expressam no sistema urbano. Concomitantemente, reconhece-se a relevância que dispositivos comunicacionais móveis e as plataformas digitais podem ter para o efeito.

\section{Dispositivos comunicacionais móveis, plataformas digitais e mapping}

Os dispositivos comunicacionais móveis (smartphones, tablets, etc.) permitem criar e emitir informação em tempo real, isoladamente ou em rede, podendo o cidadão participar na produção de conteúdos a incluir no estudo da forma urbana. Reconhece-se (principalmente a partir da década de 1960) um crescente interesse sobre como a cidade é transformada e como as dinâmicas, a participação e o papel dos citadinos têm implicações em processos de reconfiguração urbana (Mumford, 1961; Smithson e Smithson, 1967). Assim, mais do que a questão tecnológica e suas capacidades, realça-se a dimensão cultural envolvida neste processo. De acordo com Nummi e Tzoulas (2015, p. 167): 'As principais características de mapeamento cultural incluem um foco sólido nos cidadãos e uma abordagem bottomup. Como método, um levantamento representa fundamentalmente o oposto, uma abordagem top-down, onde os residentes são objetos de estudo em vez de participantes próativos ou parceiros em interação.' (tradução livre dos autores)

Verificam-se novas formas de gerar e consumir informação, que se traduzem numa nova cultura: a 'cibercultura', que Lemos (2003) define como forma sociocultural que emerge da relação simbiótica entre sociedade, cultura e novas tecnologias comunicacionais e digitais. Esta definição direciona para a noção de 'inteligência coletiva' em contexto de relações em rede, que Lévy (1998, p. 28) define como 'uma inteligência distribuída por toda parte, incessantemente valorizada, coordenada em tempo real, que resulta em uma mobilização efetiva das competências'. A designada 'era informacional', que Santos (1994) classifica de período 'técnicocientífico-informacional', assenta na velocidade e fluidez de informação, 'liquidificando' a noção de distância (tornando-a essencialmente relativa). Conforme Ortega e Bayón (2015, p. 10) referem: 'Os cidadãos não são mais consumidores passivos dos espaços alcançados, mas recriam estes espaços com interpretações que trazem novos significados emergentes dos interesses de cada um, procuras e experiências. Estes novos significados são então transferidos para redes onde eles são socializados.' (tradução livre dos autores)

A continuada ligação / conexão entre objetos, pessoas e informações (relacionadas com a localização geográfica) - onde 'os lugares e objetos passam a dialogar com dispositivos informacionais, enviando, coletando e processando dados a partir de uma 
relação estreita entre informação digital, localização e artefactos digitais móveis' (Lemos, 2008, p. 207) - tem vindo a consolidar uma cultura de informação geolocalizada, onde se anota digitalmente e se consulta localmente fluxos de dados de lugares, de indivíduos, de acontecimentos, de memórias e vivências. Transforma-se o modo como se perceciona o espaço urbano, alterando-se-lhe significados e identidade.

No contexto de processos comunicativos e informacionais, Argan (1998 [2005], p. 235) entende que sai reforçado o papel da cidade, dado que (como refere) consubstancia-se um 'aparato de comunicação; comunicação no sentido de deslocamento e de relação, mas também no sentido de transmissão de determinados conteúdos urbanos'. Conformam-se sistemas comunicacionais de troca e partilha de informações, potenciados pela computação ubíqua (a designada 'internet das coisas'), nos quais são determinantes tecnologias de informação e comunicação associadas a médias locativos, instigando e estimulando fluxos comunicacionais. De acordo com Manovich (2006), no âmbito deste tipo de interdependência, conformam-se 'realidades híbridas, aumentadas', ou segundo Beslay e Hakala (2005) - territórios ou 'bolhas digitais'. Em alternativa, como mencionado, Silva (2006) alude a espaços híbridos e espaços conectados, móveis e sociais, enquanto Santaella (2008) indica espaços intersticiais e Lemos (2009b), como referido, avança com a noção de territórios informacionais.

No quadro destas referências, advoga-se no artigo que o desenvolvimento de mapping de dinâmicas sociais e de apropriação espacial contribui para que a análise morfológica ganhe amarrações mais intrincadas no que se refere ao vínculo que se estabelece entre forma urbana e dinâmicas quotidianas que os indivíduos desenvolvem na usufruição de espaços da cidade - transformando-a a partir de práticas diárias e podendo enunciar perceções pessoais e subjetivas que (quando tratadas sistemática e coletivamente) acrescentam densidade ao conhecimento sobre formas e dinâmicas urbanas. Tem-se destacado, para o efeito, o contributo de dispositivos comunicacionais móveis e de plataformas digitais, para além de abordagens morfológicas resultantes do aprofundamento dos designados 'métodos formais' (Viana et al., 2015), como os Sistema de Informação Geográfica (SIG). A articulação entre ambos e a respetiva correlação com o potencial que a internet e o acesso genérico (e em tempo real) a dados digitais têm no mapeamento de espaços urbanos a partir da experiência individual dos mesmos, aumenta a 'geografia' da cidade - desdobrando-a dimensionalmente (quer física, quer em termos de apreensão e vivência dos seus sítios e lugares). Atendendo a Ortega e Bayón (2015, p. 11): 'O mapeamento cultural não só regista o impacto material do espaço (a sua organização, propriedades, principais funções) mas também os valores simbólicos anexados a estes atributos (memórias, rituais, linguagens). Complementarmente ao que é tangível e simbólico, o mapeamento cultural regista o invisível: o que não está lá; ausente; em falta; mas que é sentido e afirmado.' (tradução livre dos autores)

Da interdependência surgida na noção de forma-dinâmica (por via de dinâmicas sociais e da apropriação espacial) constata-se que quando se traça o redesenho cartográfico do conjunto de elementos urbanos que organizam a cidade é importante articulá-lo com dinâmicas rastreadas e fluxos gerados. A combinação de abordagens morfológicas cruzadas com diferentes dados (que permitem relacionar informação quantitativa e perceção qualitativa) possibilita conceptualizar diagramas síntese da forma-dinâmica com base em mapeamentos colaborativos em plataformas digitais. Resultam novos mapas ('aumentados') da cidade, contrapostos à cartografia que 'convencionalmente' é utilizada para mostrar a respetiva forma urbana (identificando vias, edifícios e parcelas).

Através do mapping torna-se gráfica a correlação registada entre forma e dinâmica da cidade, espacializando o intersubjetivo, as inter-relações e as interações, em que, adaptando Montaner (2014, p. 175): 'Partimos do aparentemente mais arquitetónico (...), para enfatizar um sistema geométrico que reúne qualidades diferentes num único dispositivo, com a dupla capacidade de interpretar as experiências fornecidas pela realidade e de se projetar no futuro com formas de matéria construtiva ainda não definida. Experiências e ativismos têm servido para questionar e 
superar exercícios diagramáticos autónomos e arbitrários (...). Diagrama, experiência e ação sobrepõem-se e complementam-se na procura de uma arquitetura humana e de síntese, contextual e complexa.' (tradução livre dos autores)

Regressando a Ortega e Bayón (2015, p. $11)$, pode-se acrescentar que o mapping ' (...) também serve para detetar as lacunas entre o que existe e o que é necessário, entre o que é planeado e o que é adequado. Noutras palavras, é uma ferramenta para destacar e compartilhar décalage (incompatibilidade) entre os desejos dos cidadãos e o planeamento institucional.' (tradução livre dos autores)

Complementarmente, os mesmos autores (Ortega e Bayón, 2015, p. 11), referem que: 'O mapeamento é (...) a caligrafia da cidade e forma novas maneiras de interagir com a realidade urbana. Ao mesmo tempo, é ler a cidade porque confere aos tipos de interação significados e valor únicos, que podem ser partilhados Ao contrário de planeamento, o mapping não é apenas desenvolver conteúdo material, mas torna-se uma tática imbatível de tornar o intangível valioso e visível'.

A produção de mapping, salientando o reconhecimento, validade e a espacialização do que que é intangível é exponenciada pelo recurso a dispositivos comunicacionais móveis que se encontram equipados com GPS, nos quais a maioria das suas aplicações recorre à localização dos utilizadores (por exemplo, as fotografias conseguidas através da utilização de câmara incorporada em smartphone podem ter ativada a respetiva indicação de localização, encontrando-se automaticamente georreferenciadas; ao compila-las, é possível visualizar o rastreamento do percurso realizado para a sua captura).

A conjugação do mapping no estudo da forma urbana enquadra-se quer em abordagens morfológicas na análise de cidades sujeitas a processos de urbanização auto-organizados e de rápida transformação, como a contextos urbanos genericamente estabilizados, mas em que, conforme Durão (2009, p. 405): 'Para além de implicações funcionais, também significados simbólicos devem ser considerados quando se lida com formas culturais tangíveis e intangíveis, em contextos que necessitam promover espaços para a inovação contínua e respostas emocionalmente espontâneas - um lugar no qual se viver.' (tradução livre dos autores)

O mapping de dinâmicas sociais e apropriação espacial tem implícita uma focagem de pendor mais topológico do que tipológico, resultante da componente locativa que marca a sua conceção. Para justificar esta opção, adapta-se Mehrotra (2013, pp. 9-10): '(...) A arquitetura é, claramente, a manifestação da cidade estática. Enquanto a cidade estática depende da arquitetura para sua representação, já não é possível ler a cidade a partir de uma única imagem. Por seu lado, a cidade cinética não é percecionada através de sua arquitetura, mas por espaços, que detêm valores associativos e suportes de vida. Padrões de ocupação determinam a sua forma e perceção. É um urbanismo indigente que tem a sua lógica local particular.' (tradução livre dos autores)

Torna-se necessário rastrear in situ padrões de ocupação pelos quais os citadinos aculturam e se apropriam de espaços urbanos, constatando como a forma urbana também resulta da prática diária dos indivíduos na usufruição da cidade - expressando em mapas de dinâmicas e em mapeamentos dinâmicos essas vivências.

A profusão de atividades e usos que ocorrem nos mais variados lugares requer $o$ reconhecimento que os fluxos são aspetoschave para a análise da forma urbana. Assim, revela-se determinante rastrear vivências espaciais e dinâmicas urbanas, como referido, mapeando-as no sentido de lhes conferir visibilidade na forma urbana (como têm as ruas, as parcelas e os edifícios, por exemplo). O propósito de conferir visibilidade prende-se com a noção de lhes outorgar uma dimensão existencial que deve ser enquadrada e atendida na análise morfológica.

Seguidamente, apresentam-se dois estudos de caso nos quais se ensaiou a análise da forma-dinâmica urbana através do mapping de dinâmicas e da apropriação espacial. Constituíram dois momentos relevantes na convergência entre a aplicação da metodologia 'Trac(k)ing': tracing by tracking - a kinetic approach, (Viana, 2015) e a investigação desenvolvida por Carvalho (2016) no âmbito da sua Tese de Doutoramento em Média-Arte Digital, com o título: 'Média-arte locativa e mapeamentos dinâmicos na compreensão de fluxos urbanos: o contributo do dispositivo 
móvel na atividade do caminhar como prática artística'.

\section{Caso de estudo 1: Vale de Chelas (Lisboa)}

O Vale de Chelas (Lisboa) revela espaços urbanos fragmentados / intersticiais, com estratos populacionais muito distintos (social, económica e culturalmente). É uma área com dinâmicas sociais endógenas e exógenas de difícil relação, que dificulta a apropriação espacial e construção de vivências urbanas partilhadas entre comunidades de origem cigana, africana, do leste europeu, entre outras (muito 'etnocentradas' e pouco permeáveis a contactos cruzados com indivíduos exteriores aos seus grupos).

A oportunidade de abordar esta parte de Lisboa surgiu no 'Módulo 1: Contextos de Urbanização e Morfologia' do Curso de Especialização em Territórios Colaborativos: Processos, Projeto, Intervenção e Empreendedorismo do Instituto Universitário de Lisboa (ISCTE-IUL). Uma das problemáticas equacionadas prendia-se com a análise morfológica daquele tecido urbano e respetiva forma-dinâmica, contando com o envolvimento de população na usufruição do Vale de Chelas. Perspetivava-se aferir o potencial da aplicação de mapeamentos dinâmicos no estudo da forma urbana local. Para o efeito, instalaram-se nos smartphones dos participantes do 'Módulo 1' as aplicações 'myTracks' ou 'Os Meus Mapas', consoante os sistemas operativos dos mesmos.

Posteriormente, explicou-se aos estudantes como poderiam cruzar (a partir de dispositivos comunicacionais móveis) dados de matriz quantitativa com os de pendor mais qualitativo (provindos de vídeos, fotos e anotações pessoais). Acordou-se estruturar a análise morfológica assente em processos mediáticos locativos e na produção de cartografia multidimensional. Os percursos realizados foram rastreados e mapeados, tendo-se sugerido que se fizessem anotações (in loco e em tempo real) sobre o que os participantes sentiam e inferiam nos espaços urbanos analisados.

Os percursos foram comentados, não só a partir do diálogo e contacto (exploratório e estruturado) com a população do Vale de Chelas, mas inclusive na troca de impressões pessoais em sede de trabalho de grupo. $\mathrm{Na}$ plataforma Google - 'Os Meus Mapas', foi criado um mapa colaborativo e (recorrendo ao e-mail dos intervenientes) autorizou-se a sua partilha e participação como coautores. $\mathrm{O}$ mapa foi denominado de Mapeamento Colaborativo de Vale de Chelas (Figura 1) e pode ser consultado em: https://www.google. com/maps/d/edit?mid=z4aHPsAtkAjw.kdgl456 980uA\&usp=sharing).

Ao mapa criado foi associada grande quantidade de notas e observações, indicadas em percursos realizados com apoio de dispositivos comunicacionais móveis, consideradas relevantes para o estudo da forma urbana do Vale de Chelas e determinantes para a compreensão dos respetivos fluxos. Constituiu um processo no qual se anotaram e anexaram imagens, mas também sons e textos dos e sobre os espaços urbanos, contextualizando informação que acrescentou densidade às dinâmicas sócioespaciais individuais e espessura à análise morfológica. A realização do mapa coletivo foi útil no estudo multidimensional da forma urbana local. Complementarmente, nele foram sendo testadas estratégias desenvolvidas pelos estudantes do curso, obtendo comentários e sugestões (feedback) em tempo real de outros colegas que (em ambiente digital) discutiam o que ia sendo ensaiado no mapa coletivo do Chelas (dado ter ficado acessível na internet, bem como a informação nele constante, onde as alterações que iam acontecendo eram imediatamente reconhecidas por todos). Conjugaram-se grafismos, som, imagem e movimento (áudio, fotografia, textos, vídeos, ligações a outras páginas de internet, etc.) abrindo caminho a novas possibilidades instrumentais e metodológicas no estudo da forma urbana.

O mapa, ao permitir ser acedido in loco para consulta e / ou para o acrescentar continuado de informação morfológica e propostas de transformação, desdobrou, relacionou e proporcionou nexos, conexões e fluxos comunicacionais alimentados por reflexões pessoais, narrativas individuais e olhares críticos diversificados sobre vivências individuais e coletivas. O mapa digital, colaborativo, como expressão de múltiplas realidades interdimensionais, disponibilizando conhecimento e auxiliando no estudo da forma urbana (e seus fluxos, dinâmicas e 


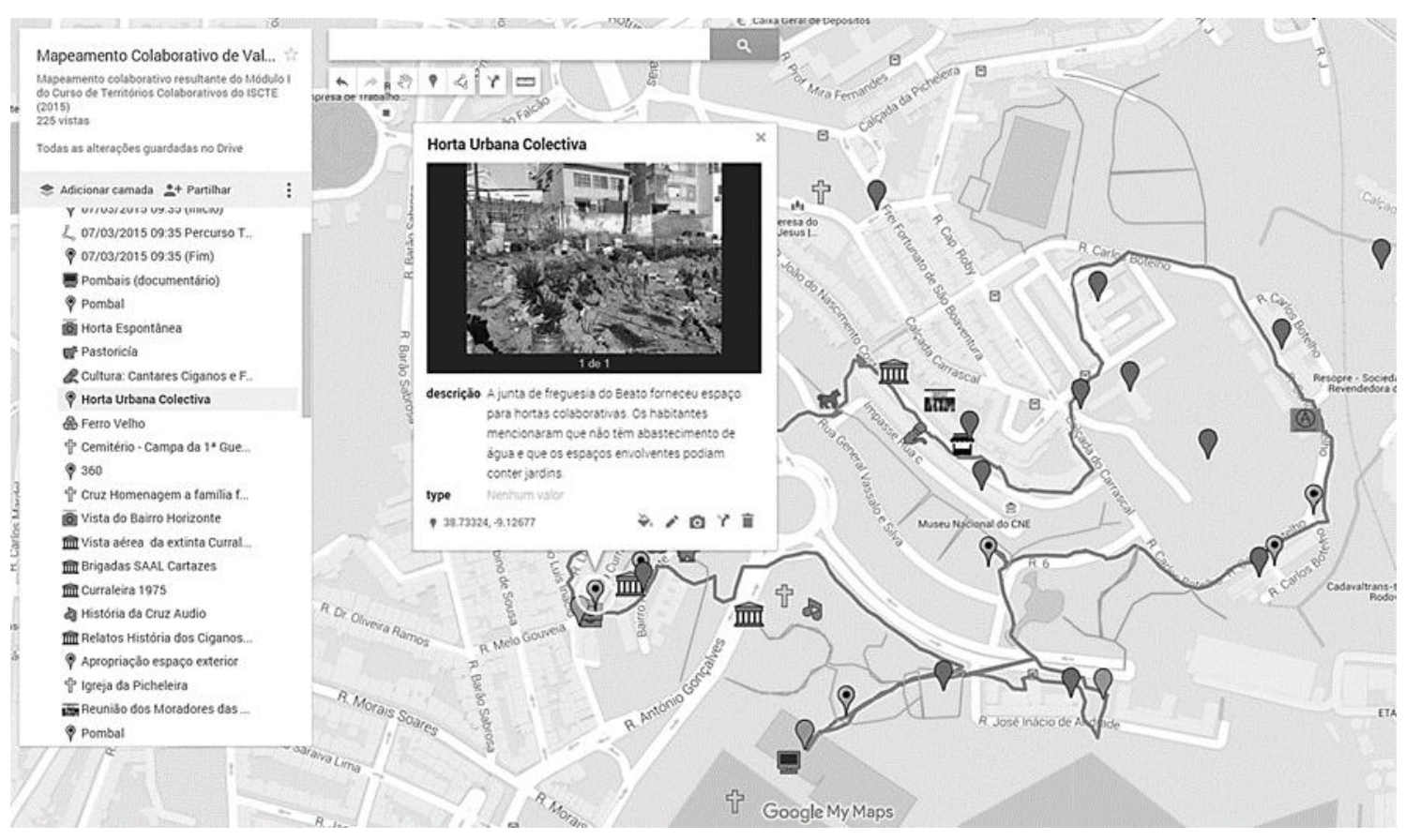

Figura 1. Exemplo de anotação (fotografia e comentário individual georreferenciado) no mapeamento colaborativo do Vale de Chelas, realizado por participantes do Módulo 1: Contextos de Urbanização e Morfologia do Curso de Especialização em Territórios Colaborativos: Processos, Projeto, Intervenção e Empreendedorismo do ISCTE, 2015.

apropriações sócio-espaciais), tornou-se produto cultural ao promover e facilitar a participação ativa da população, estimulando a interação social. Desenharam-se mapas coletivos nos quais se equacionou a análise morfológica estabelecendo indicadores sobre vivências, tendências e padrões expressos em mapeamentos dinâmicos que informaram sobre atributos espaciais, comportamentais e sensoriais. Consolidou-se a operacionalidade entre abordagens morfológicas, que possibilitou leituras desdobradas e aumentadas de espaços urbanos, contribuindo para níveis acrescentados do estudo da forma urbana acomodando a diversidade das múltiplas dimensões equacionadas.

Em síntese, a atenção dada às dinâmicas quotidianas desencadeadas pelos diferentes usufruidores dos espaços urbanos resulta da perspetiva que os fluxos e as dinâmicas urbanas que decorrem na cidade também 'desenham' as suas formas. A análise morfológica não se ficou apenas sobre a dimensão tangível da vida urbana, mas contemplou vivências diárias (e respetiva criatividade com que são nutridas) para além do sentido prático com que são desenvolvidas na resposta a constrangimentos e fragilidades urbanas. A assemblagem entre autoorganização e forma urbana é devidamente equacionada na seguinte citação (Batty e Hudson-Smith, 2012, p.18): 'A nossa nova compreensão de como as cidades funcionam baseia-se em dinâmicas bottom-up. As cidades são construídas por ações exercidas por indivíduos em nome próprio ou de coletividades maiores, agências e grupos, principalmente configurados como ações locais. Padrões globais emergem em diferentes partes da cidade expressando a tomada de decisões de rotina, que se combinam para produzir ordem em escalas cada vez mais altas. (...) Em geral, autoorganizam-se de baixo para cima em ações locais sucessivamente encetadas, desfeitas e transformadas em processos individuais de ajustamentos locais. (...) O planeamento tradicional que contrarie tal auto-organização falhará e, neste sentido, os melhores princípios de projeto devem refletir a organização a partir de baixo para acima (bottom up).' (tradução livre dos autores) 


\section{Caso de estudo 2: Vila Nova de Cerveira (Minho) / Goiàn (Galiza)}

Uma outra experiência preparada no âmbito do estudo da forma-dinâmica urbana através do mapping de dinâmicas sociais e da apropriação espacial (com contributo de dispositivos comunicacionais móveis com tecnologia GPS e acesso à internet móvel), desenvolveu-se na Escola Superior Gallaecia (ESG), no Workshop de Urbanismo 'Trac(k)ing': tracing by tracking - a kinetic approach, onde não só se aprofundou $\mathrm{o}$ processo relativo à produção de mapeamentos dinâmicos e participativos, como também se atendeu à articulação destes com a abordagem configuracional ou space syntax (Hillier e Hanson, 1984). O interesse em entrecruzar mapeamentos dinâmicos (conforme a referida Tese de Doutoramento de Carvalho, 2016) no estudo da forma urbana e compreensão de dinâmicas sociais (e apropriação espacial) com a análise configuracional, prendeu-se com o facto de também nesta abordagem se ter em linha de conta fluxos e como a configuração física dos espaços condiciona vivências urbanas.

Justificou o Workshop de Urbanismo na ESG a perspetiva de se avançar para uma nova ponte pedonal sobre o Rio Minho - hipótese em discussão entre ambos os municípios, Vila Nova de Cerveira (Minho, Portugal) e Tomiño (Galiza, Espanha), ligando as margens de Vila Nova de Cerveira e Goián, pequena vila galega do município de Tomiño. Interrogavase quais os fluxos e que tipo de apropriações alocadas a espaços urbanos de ambas as vilas poderiam ser protagonistas na decisão da localização da nova passagem pedonal entre as margens do Rio Minho. Esta dúvida tornara-se ainda mais relevante quando se começou a perceber, localmente, que uma mera abordagem técnica apontaria para o posicionamento da ponte no sítio correspondente à distância mais curta entre margens. No entanto, havia a suspeita que a resposta a dar não seria estritamente técnica e / ou económica (menor preço da construção da ponte por via do respetivo vão mais curto). Considerou-se relevante compreender dinâmicas sócio-espaciais no estudo da forma urbana local para, a partir daí, tomar-se uma decisão mais apoiada quanto às diferentes dimensões morfológicas da problemática.

Combinando, de modo integrado, técnicas e métodos de análise urbana, procedeu-se à realização de mapa colaborativo com contributo do dispositivo móvel e da ligação à internet. Instalaram-se as aplicações 'Os Meus Percursos' e 'myTracks'. Foi criado e partilhado o acesso (em modo de edição) ao mapa coletivo. Avançou-se para o estudo da forma urbana realizando-se rastreamentos de fluxos, dinâmicas e apropriações. Pretendeuse verificar as marcas que nela perduravam relativas a atividades e usos. A redescoberta individual e coletiva de características e vivências multidimensionais de espaços urbanos de Vila Nova de Cerveira e Goiàn remeteu os participantes no Workshop para a imersão em memórias e elementos urbanos locais.

A produção de mapping de dinâmicas sociais e de apropriação espacial, integrado na análise morfológica, assentou em rastreamentos e mapas expressando fluxos gerados. $\mathrm{O}$ intuito foi compreender espaços urbanos percorridos e quanto tempo os participantes se detiveram em sítios concretos de Vila Nova de Cerveira e de Goiàn. Para o efeito, foi significativo o potencial instrumental de aplicações como a referida 'myTracks' (entre outras). Os rastreamentos dos percursos foram exportados (em extensão .gpx ou .kml) para as plataformas CartoDB (https://cartodb.com/) e Google Maps (https://maps.google.pt/).

Os mapas foram trabalhados no sentido de serem acrescentadas experiências, vivências, impressões e sensações captadas em vídeos, fotos, desenhos, cartografia, comentários, diálogos e anotações, que traduziam aspetos e características dos elementos urbanos de ambas as vilas. $\mathrm{O}$ mapa colaborativo de Vila Nova de Cerveira e Goián (Figura 2) foi disponibilizado para consulta, partilha e acréscimo de dados online, em: https://www. google.com/maps/d/edit?mid=z4aHPsAtkAjw kEMvc-5AyMEk\&usp=sharing.

A anotação in loco, no plano digital (recorrendo a smartphones), permitiu que os estudantes compreendessem espaços urbanos em modo multidimensional, consolidando perceções sócio-espaciais individuais em sistema aberto de partilha por via do acesso à internet móvel. 

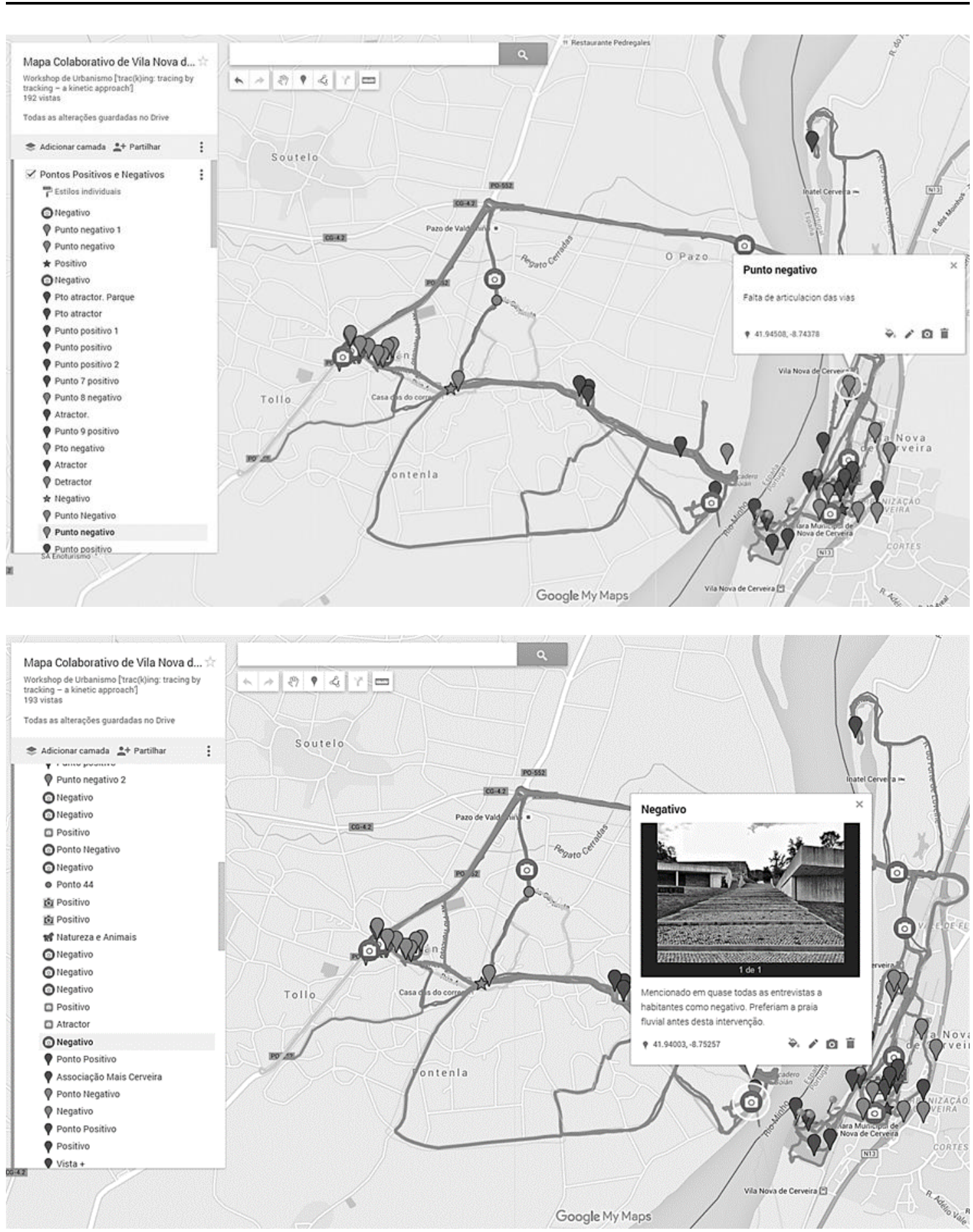

Figura 2. Mapa relativo a diferentes percursos rastreados e anotação de espaços e / ou elementos urbanos notáveis e dissonantes indicados pelos participantes no Workshop de Urbanismo da ESG, 2015.

A apreensão espacial procedia de um processo de desdobramento de vivências pessoais, em que - digitalmente - eram interrelacionadas com as de outros colegas em tempo real, permitindo ter feedback de vários espaços urbanos em simultâneo. A interdependência entre experiências individuais potenciou lógicas colaborativas por via da troca constante de inputs dos usufruidores dos espaços urbanos analisados, tornando possível que cada um deles fosse tendo conhecimento de aspetos sobre espaços 
nos quais não estariam e que podiam ser relacionados com aqueles em que se encontravam.

A hibridização de abordagens morfológicas no estudo da forma urbana (mediada por dispositivos comunicacionais móveis) acrescentou densidade à identificação de elementos urbanos e ao estabelecimento de padrões de uso dos espaços urbanos. A experiência conferiu níveis mais complexos de interdependência na análise morfológica. Alcançaram-se leituras de dinâmicas espaciais, a partir das quais foi possível verificar regras implícitas de vivências sobre a forma urbana de Vila Nova de Cerveira e de Goiàn. Com o conjunto de mapas coletivos de dinâmicas e de mapeamentos dinâmicos foi possível comparar e sistematizar parâmetros e definir indicadores sobre movimentos e apropriações espaciais. $\mathrm{O}$ entendimento de como a configuração dos espaços urbanos é interdependente do modo como é apropriado (e como o movimento nele acontece) afigurou-se relevante no estudo da forma urbana, dado considerar-se que a apreensão urbana é condicionada pela perceção que se vai tendo dos espaços urbanos. A compreensão in situ envolveu sensorialmente a resposta do corpo a estímulos e condicionalismos dos espaços urbanos e seus elementos. Enlaçando mapeamentos dinâmicos e análise configuracional, procurou-se demonstrar a confluência de resultados ao nível da deteção de fluxos urbanos a partir de diferentes ambientes digitais (CartoDB e Depthmap).

\section{Conclusões}

Em síntese, reforça-se a perspetiva que a convergência relativa à interoperatividade e à multidimensionalidade de leituras que podem ser associadas na análise morfológica potencia e amplifica o estudo da forma urbana. A comparação entre abordagens e a inter-relação de métodos de análise morfológica permite tornar explícito, estruturadamente, o sentido das apropriações e das dinâmicas geradas na forma urbana, considerando-se a interdependência entre a configuração física do sistema espacial, a perceção que dele se tem e que padrões de usos se conformam nos seus espaços. Os casos de estudo sucintamente indicados, relativos ao Vale de Chelas e a Vila Nova de Cerveira / Goiàn, serviram para ensaiar como a combinação de modos de análise morfológica 'tradicional' com novos processos de compreensão do espaço urbano pode ser estruturada e que tipo de alcance e resultados se poderá esperar desta conjugação. $\mathrm{O}$ artigo coloca a tónica na necessidade de ampliar a integração entre abordagens morfológicas (analógicas, digitais, qualitativas, quantitativas, entre outras) aprofundando dimensões intangíveis em suportes tangíveis - desdobrando nexos entre formas e dinâmicas urbanas e enlaçando o estudo dos elementos urbanos com a compreensão dos fluxos que entre eles se geram a partir das vivências (individuais e / ou coletivas) que neles decorrem.

É significativa a articulação de vínculos tripartidos entre lógicas espaciais, relacionais e percetivas na aferição da inteligibilidade multidimensional de espaços urbanos. É na relação dialógica entre o traçar e o rastrear que se revelam dinâmicas espácio-sociais que ampliam o estudo da forma urbana $e$ acrescentam densidade à análise morfológica. O estudo da forma-dinâmica urbana (Viana, 2015), através do mapping de dinâmicas sociais e da apropriação espacial, tem implícita a convicção que está em curso uma alteração significativa no modo como os espaços urbanos são representados e como a cartografia 'aumentada' (augmented cartographies - Viana e Carvalho, 2016) pode expressar (de maneira mais completa e plural) não só a forma urbana, mas também a diversidade subjetiva de dados de indivíduos e comunidades - crowd data (Viana e Carvalho, 2016) que a habitam (e como o fazem).

Deixa de ser relevante a adjetivação que 'usualmente' se associa ao estudo da forma urbana, passando a importar o que nela acontece. $\mathrm{Na}$ análise morfológica, mais do qualificar espaços urbanos quanto aos elementos que os estruturam, prevalecerá conjugar convergentemente forma e dinâmicas. Sobre esta perspetiva, fecha-se o artigo referenciando Ribeiro e Lima (2011, p. 39): 'Entender como os mapas, enquanto instrumentos de circulação de informações enquadrados na lógica das representações sociais, vêm se transformando, a partir do uso e da apropriação dos modelos eletrônicos, em sistemas abertos e 
colaborativos de projeção do espaço geográfico. Desta forma, a questão central visa discutir uma possível mudança nos esquemas representacionais dos territórios que estaria a ocorrer a partir do desenvolvimento de tais modelos presentes na internet.'

\section{Referências}

Argan, G. C. (1998 [2005]) História da arte como história da cidade (Martins Fontes, São Paulo).

Aymonino, C. (1977) Lo studio del fenomeni urbani (Officina Edizioni, Roma).

Batty, M. e Hudson-Smith, A. (2012) 'Discussions on systemic architecture: the liquid city', em Poletto, M. e Pasquero, C. (eds.) Systemic architecture: operating manual for the selforganizing city (Taylor \& Francis, Abingdon) 1820.

Beslay, L. e Hakala, H. (2005) 'Digital territory: bubbles', em Kidd, P. T. (ed.) (2007) European visions for the knowledge age: a quest for new horizons in the Information Society (Chenshire Henbury).

Caro, C. M. e Rivas, J. L. (1985) Arquitectura urbana: elementos de teoria y diseño (Universidad de Navarra, Pamplona).

Carvalho, I. (2016) 'Média-arte locativa e mapeamentos dinâmicos na compreensão de fluxos urbanos: o contributo do dispositivo móvel na atividade do caminhar como prática artística', Tese de Doutoramento não publicada, Universidade do Algarve, Portugal.

Castells, M. (1972) Le question urbaine (Françoise Maspero, Paris).

Castells, M. (1999 [2002]) A sociedade em redea era da informação: economia, sociedade $e$ cultura (Paz e Terra, São Paulo).

Coelho, C. D. (ed.) (2013) Os elementos urbanos (Argumentum, Lisboa).

Durão, M. J. (2009) 'Embodied space: a sensorial approach to spatial experience', Space, Propulsion \& Energy Sciences International Forum, 399-406.

Hillier, B. e Hanson, J. (1984) The social logic of space (Cambridge University Press, Cambridge).

Horan, T. A. (2000) Digital places: building our city of bits (ULI, Washington).

Jacobs, J. (1961) The death and life of great American cities (Random House, Nova Iorque).

Jenkins, H. (2006) Convergence culture: where old and new media collide (New York University, Nova Iorque).

Lefebvre, H. (1968) Le droit à la ville (Anthropos, Paris).

Lemos, A. (2003) Olhares sobre a cibercultura
(Sulina, Porto Alegre).

Lemos, A. (2007) 'Ciberespaço e tecnologias móveis: processos de territorialização e desterritorialização na cibercultura', em Médola, A. S., Araújo, D. e Bruno, F. (eds.) Imagem, visibilidade e cultura mediática (Sulina, Porto Alegre) 277-93.

Lemos, A. (2008) 'Mídia locativa e território informacional', em Arantes, P. e Santaella, L. (eds.) Estéticas tecnológicas: novos modos de sentir (EDUC, São Paulo).

Lemos, A. (2009a) 'Cultura da mobilidade', Revista Famecos 40, 28-35.

Lemos, A. (2009b) 'Arte e mídia locativa no Brasil', em Bambozzi, L., Bastos, M. e Minelli, B. (eds.) Mediações, tecnologias e espaço público: panorama crítico das artes em mídias móveis (Conrad, São Paulo) 161-78.

Lévy, P. (1998) A inteligência coletiva (Loyola, São Paulo).

Manovich, L. (2006) 'The poetics of augmented space', Visual Communication (http://vcj.sagepub.com/citmgr?gca=spvcj\%3B5 $\% 2 \mathrm{~F} 2 \% 2 \mathrm{~F} 219$ ) 219-40, consultado em 12 de Janeiro de 2014.

Mehrotra, R. (2013) 'Re-thinking the informal city', Informal Community - Area 128, 6-12.

Montaner, J. M. (2014) Del diagrama a las experiencias, hacia una arquitectura de la acción (Gustavo Gili, Barcelona).

Moughtin, C. (1996) Urban design green dimensions (Butterworth Architecture, Londres).

Mumford, L. (1961) The city in history: its origins, its transformations and its prospect (Harcourt, Brace \& World, Nova Iorque).

Nummi, P. e Tzoulas T. (2015) 'Engaging citizens in cultural planning with a web map survey', Culture and Local Governance 5, 161-73.

Ortega, C. e Bayón F. (2015) 'Cultural mapping and urban regeneration: analyzing emergent narratives about Bilbao', Culture and Local Governance 5, 9-22.

Panerai, P., Demorgon, M. e Depaule, J. C. (1980) Eléments d'analyse urbaine (Archives de l'Architecture Moderne, Bruxelas).

Ribeiro, J. C. e Lima, L. B. (2011) 'Mapas colaborativos digitais e (novas) representações sociais do território: uma relação possível', Ciberlegenda 25, 38-47.

Salingaros, N. (coord.) (2011) P2P Urbanism (Umbau-Verlag, Solingen).

Salingaros, N., Brain, D., Duany, A., Mehaffy, M. e Philibert-Petit, E. (2011) 'Socially-organized housing, a new approach to urban structure III: some of the problems facing us', Brazilian Journal of Urban Management 3, 293-308.

Santaella, L. (2008) 'A estética política das mídias locativas', Nómadas 28, 128-37.

Santos, M. (1994) Técnica, espaço, tempo: 
globalização e meio técnico-científico informacional (Hucitec, São Paulo).

Silva, A. S. (2006) 'From cyber to hybrid: mobile technologies as interfaces of hybrid spaces', Space and Culture 9, 261-78.

Smithson, A. M. e Smithson, P. (1967) Urban structuring: studies of Alison \& Peter Smithson (Studio Vista, Londres).

Soja, E. (2011) Postmodern geographies: the reassertion of space in critical social theory (Verso Books, Londres).

Trancik, R. (1986) Finding lost space: theories of urban design (Van Nostrand Reinhold, Nova Iorque).

Vegara, A. e Rivas, J. L. (2004) Territorios inteligentes (Nuevos Horizontes del Urbanismo, Madrid).

Venturi, R., Izenour, S. e Scott Brown, D. (1977)
Learning from Las Vegas: the forgotten symbolism of architectural form (The MIT Press, Cambridge).

Viana, D. L. e Carvalho, I. C. (2016) 'From crowd data to augmented cartographies', International Journal of E-Planning Research - Urban EPlanning: Recent Developments, Emergent Issues and Future Challenges (https://sites.google.com/site/ijepr2016conferenc e/abstractspdf) consultado em 24 de Março de 2016.

Viana, D. L., Morais, F. e Vaz, J. V. (2015) $3^{\text {rd }}$ Symposium Formal Methods in Architecture: book of abstracts (ESAP, Porto).

Viana, D. L. (2015) '(Auto)organização e forma urbana: combinando diferentes abordagens morfológicas na análise de Maputo', Relatório de Pós-Doutoramento não publicado, Universidade do Porto, Portugal.

\title{
Tradução do título, resumo e palavras-chave
}

The study of the urban 'form-dynamic': mapping the spatial appropriation and the social dynamics

\begin{abstract}
The paper addresses the correlation between urban form and socio-spatial dynamics, focusing on tracking urban flows by using mobile communication devices (such as smartphones and tablets). It argues for the inclusion of contemporary ways of experiencing the urban space - potentiated by digital connection and access to the internet, supported by digital platforms processing a wide variety of individual and collective data, georeferenced in real time - into morphological analysis. The profusion of activities and uses occurying in the urban space leads to the acknowledgement that urban flows are key aspects in urban form analysis. As such, tracking, and mapping, the different urban experiences is of fundamental importance. This argument relates to the convergence between the concept of urban dynamic-form and the development of mapping spatial appropriationa and social dynamics. It makes reference to the 'interoperability' and the 'multidimensionality' of readings processed in combinatorial mode in morphological analysis, widening the scope of the study of the urban form. This interrelation of morphological analysis' methods should make explicit, in a structured way, the rules underlying the dynamics detected in urban form, consolidating the interdependence between the physical configuration of the spatial system, its perceptions and the patterns of appropriation.
\end{abstract}

Keywords: morphological analysis, urban 'form-dynamic', mapping, social dynamics, spatial appropriation

\section{PNUM 2017 Vitória}

A $6^{\mathbf{a}}$ conferência da Rede Lusófona de Morfologia Urbana (PNUM) terá lugar em Vitória (capital do estado de Espirito Santo, no Brasil) entre 24 e 25 de Agosto de 2017. Esta conferência tratará de possibilidades e alcances do estudo da forma urbana na configuração e no planejamento / projeto do território e da paisagem.
Intrínsecos à problemática estão a articulação e os limites entre manutenção da memória coletiva e desejo de transformação e a construção de estratégias que assegurem a justiça socioespacial. Informações sobre os tópicos que irão estruturar o debate e o calendário de submissão serão divulgados no website do PNUM 2017, a ser lançado muito em breve. 